\title{
Gas engines secondary heat recovery to electrical energy
}

\author{
Yurii Oksen ${ }^{1, *}$, Olena Trofymova ${ }^{1}$, Oleksandr Bobryshov ${ }^{1}$, Anatolii Lukisha ${ }^{2}$, and \\ Volodymyr Pryvalov \\ ${ }^{1}$ National Technical University "Dniprovska Politechnika”, 49005, Dnipro, Yavornytskoho Ave., 19, \\ Ukraine \\ ${ }^{2}$ Institute of Geotechnical Mechanics named by N. Poljakov of National Academy of Sciences of \\ Ukraine, 49005, Dnipro, Simferopolska Str., 2a, Ukraine
}

\begin{abstract}
The schema for gas engine waste heat recovery to electrical power by dual circuit power generation unit with different working agents has been developed. The method and the most efficient power generation unit heat mode calculation algorithm under the conditions of the given restrictions on the temperature differences in the heat exchangers has been developed. Based on the mathematical modeling of heat modes it has been stated that $4200 \mathrm{~kW}$ of heat power can be utilized to generate $520 \mathrm{~kW}$ of electrical power for JMS 620 gas engine. It has been calculated that the efficiency of secondary heat recovery to electrical power reaches $12.3 \%$ which leads general efficiency increase for a gas engine from 42.9 up to $50.0 \%$
\end{abstract}

\section{Introduction}

In recent years, Ukraine has been actively developing energy-saving heat pump and cogeneration technologies for using low-grade natural heat, secondary and waste heat of industrial plants. The possibilities are being explored to more fully utilize fuel resources, including methane produced by coal mine degassing systems $[1-7]$. The most effective way to use this methane is to burn it in cogeneration gas engine units, which generate electrical energy and secondary heat for heating systems [1, 7]. Nowadays, two large cogeneration projects have been implemented in Ukraine. The first one is at the Mine named after O. Zasiadko and the second one is in Public Joint-Stock Corporation (PJSC) "Pokrovske Mine Office". On "Mine name after O. Zasiadko" operate twelve, and in PJSC "Pokrovske Mine Office" six gas engines JMS 620 manufactured by GE Jenbacher. Each gas engine unit generates $3035 \mathrm{~kW}$ of electrical and $2920 \mathrm{~kW}$ of thermal power. The sources of heat are lubricating oil, gas-air mixture after turbocharging, cylinders, and exhaust gases. Thermal powers of these sources are shown in Figure 1 [7].

Water of cooling system of the gas engine can be heat from 70 up to $100{ }^{\circ} \mathrm{C}$. Exhaust gases are cooled from 420 to $140{ }^{\circ} \mathrm{C}$.

In case when gas engines are located far from the heat consumers, the secondary heat is

*Corresponding author: oksenui49@gmail.com 
not used and discharged into the environment, such as, for example, at the mine named after O.Zasiadko. This significantly reduces the efficiency of engines and leads to environmental pollution. Such cases may be not uncommon. Therefore, the problem of secondary heat recovery of the gas engines is considered to be argent.

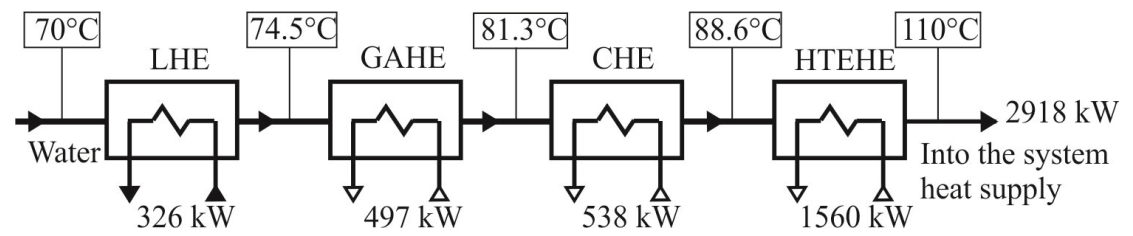

Fig. 1. Typical diagram of water cooling system for gas engine JMS 620: LHE - lubricating oil heat exchanger; GAHE - gas and air mixture heat exchanger; CHE - cylinder heat exchanger; HTEHE high temperature exhaust heat exchanger.

The aim of the study is to develop an effective schema for converting the secondary heat of the gas engines into electrical energy and determining the indicators of its energy efficiency.

\section{Methods}

The scheme in Figure 2 is one of the simplest ones [8].

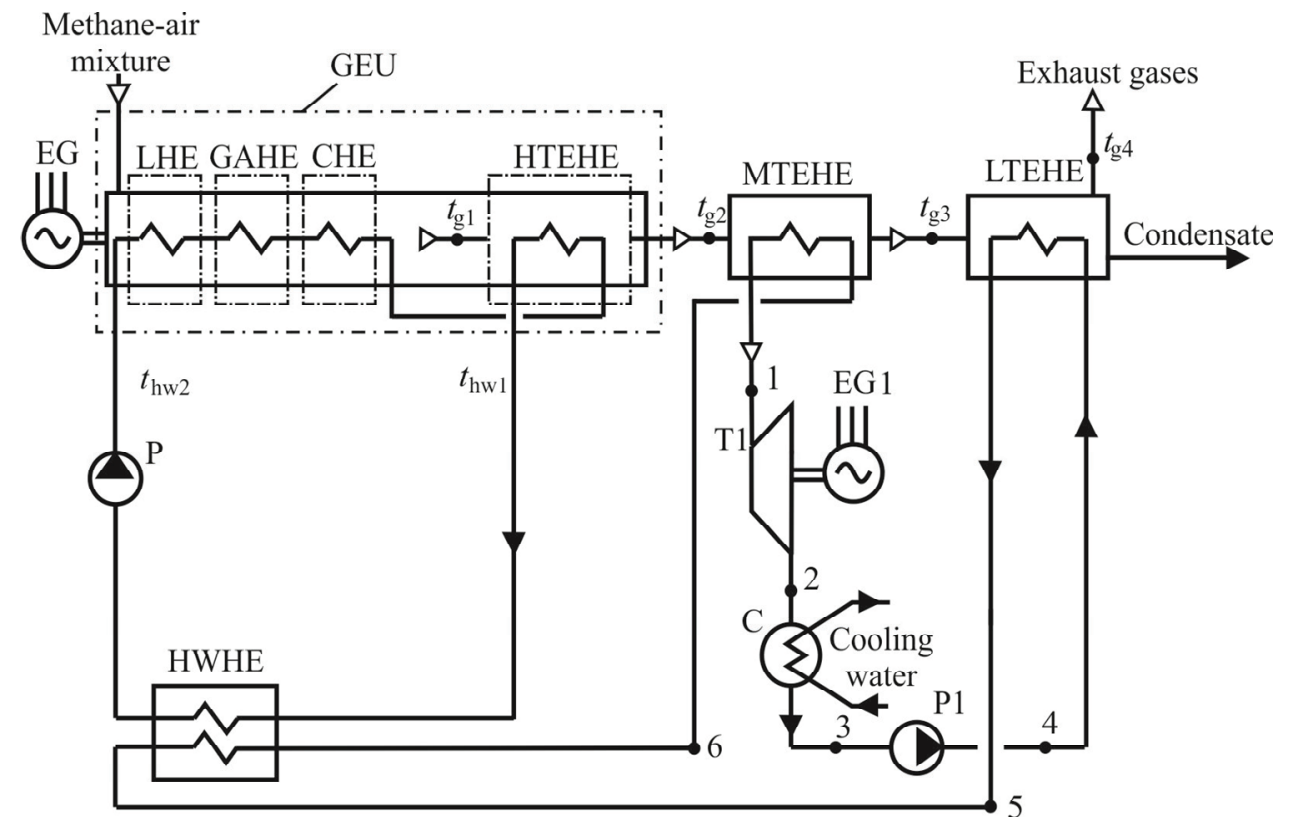

Fig. 2. Schematic diagram of gas engine secondary heat recovery system by single-circuit power generation unit: GEU - gas engine unit; MTEHE - medium temperature exhaust heat exchanger; LTEHE - low temperature exhaust heat exchanger; HWHE - hot water heat exchanger; C condenser; P, P1 - pumps; EG, EG1 - electricity generators.

The schema provides an ability to transfer the heat of the hot water with $110^{\circ} \mathrm{C}$ and exhaust gases with $140{ }^{\circ} \mathrm{C}$ to low-boiling working fluid of power generation unit (PGU) operating with Rankine cycle.

Heat transfer is carried out in a hot water heat exchanger and exhaust heat exchangers medium-temperature exhaust gas heat exchanger and low-temperature exhaust gas heat 
exchanger. These heat exchangers play the role of vapor generator in PGU. The resulting vapor of working fluid goes to the turbine T1, in which it produces work that is converted by electric generator EG1 into electrical energy. After the turbine the vapor is sent to the condenser $\mathrm{C}$, in which it gives off heat to the cooling water and condensed. The circulation of low-boiling working fluid in the circuit is maintained by the pump P1.

As a result of simulating the thermal modes of the PGU according to this scheme, performed for the case of utilization of the secondary heat of the gas engine JMS 620 and usage of Freon R142b and ammonia as the working fluids, it has been found that the schema allows generating up to $260-280 \mathrm{~kW}$ of electricity. It has been calculated that $3200-3900 \mathrm{~kW}$ of heat power can be utilized with the efficiency of electricity generation is $0.065-0.095$ [8].

Such a low efficiency of this scheme is explained, first of all, by large exergy losses during the heat transfer from exhaust gases to the water of the engine cooling system in high-temperature exhaust gas heat exchanger. These losses can be significantly reduced if the heat of the exhaust gases taken in this heat exchanger is converted into operation and electricity in a separate circuit of the PGU. The schema for converting the secondary heat of the gas engine into electricity using a dual-circuit PGU is shown in Figure 3.

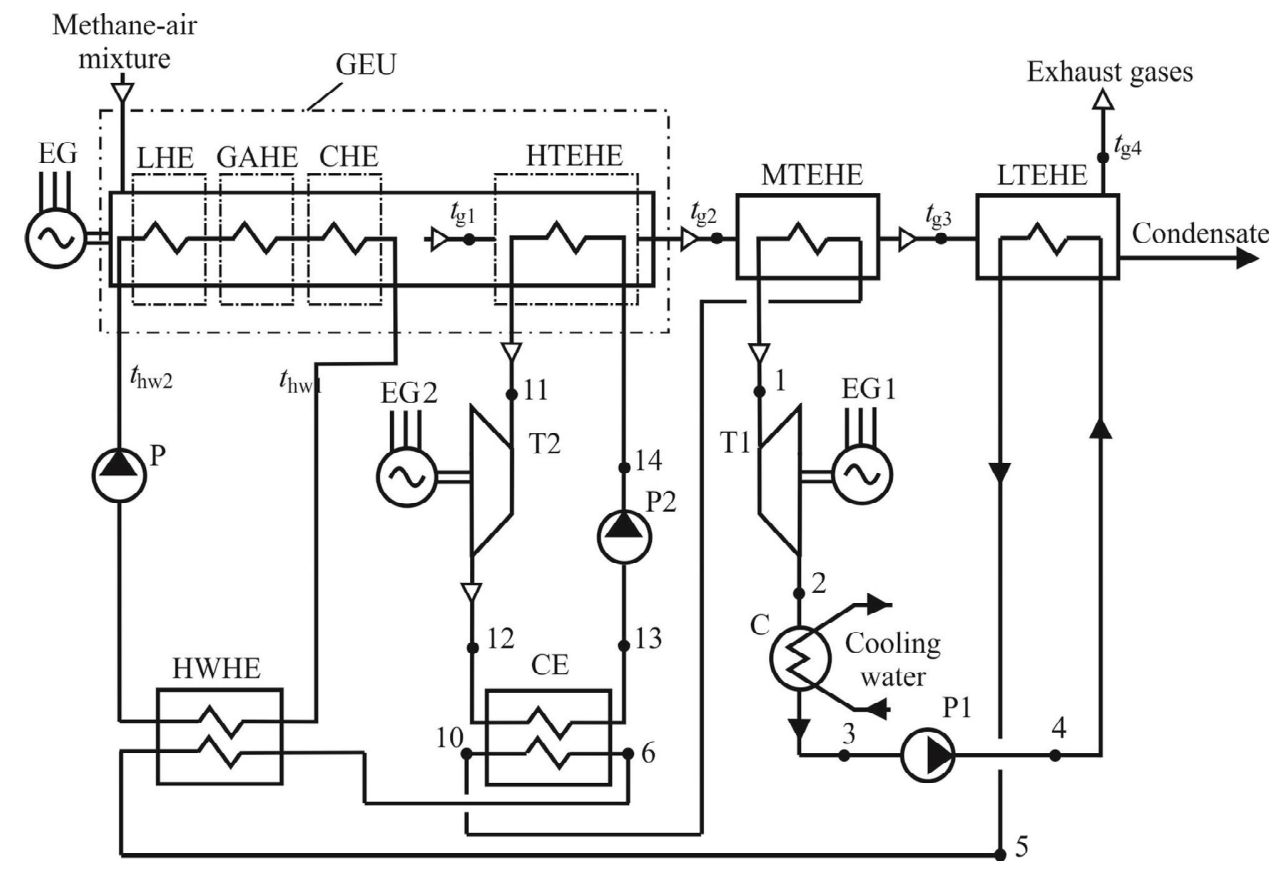

Fig. 3. Schematic diagram of gas engine secondary heat recovery with two-circuit power generation unit.

In the above scheme, we can distinguish a low-temperature circuit 1-2-3-4-5-6-10-1 and high-temperature circuit 11-12-13-14-11. In the high-temperature circuit, the highgrade exhaust heat and in the low-temperature circuit, the low-grade heat of the hot water of the engine cooling system and the residual heat of the exhaust gases are converted into work. Each circuit, practically speaking, is a PGU operating with a Rankine cycle. In this case, the heat of the condensation of the working fluid of the high-temperature circuit is transferred to the low-temperature circuit in the condenser-evaporator CE. It allows to avoid low temperatures and condensation pressures of the working fluid of the hightemperature circuit and to improve the weight and size characteristics of PGU.

Thermodynamic cycles of changing the state of working fluid in the circuits are shown 
in Figure 4 in $T, s$ - coordinates ( $T$ - is temperature, $s$ - is entropy).

The numbers of the characteristic points of the cycles correspond to the numbers of the points indicated in the diagram of the PGU (Fig. 3). For the high-temperature circuit, the cycle is depicted for the case of using as a working fluid substances for which $(\partial T / \partial s)_{x=1}<0$ and that boiled isobarically and condensed at a constant temperature (water vapor). For the low-temperature circuit, the cycle is depicted for a mixed working medium of the type of butane-pentane mixture, for which $(\partial T / \partial s)_{x=1}>0$ and that boiled isobarically and condensed at a variable temperature.

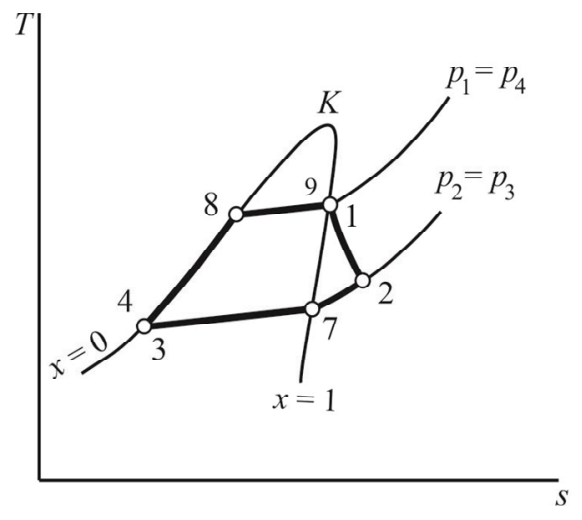

a)

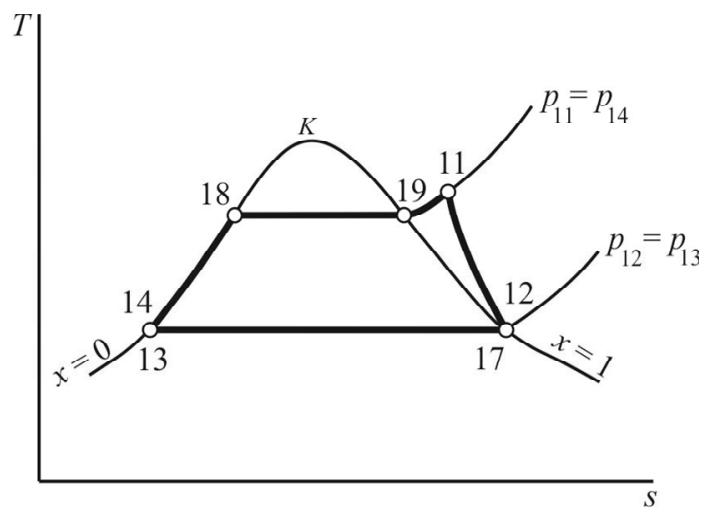

b)

Fig. 4. Thermodynamic cycles of working fluid changes in low- (a) and high temperature (b) circuits.

In this analysis, water is taken as the working fluid for the high-temperature circuit, and for low-temperature circuit a mixture of butane and pentane, $85 \%$ and $15 \%$ by weight, respectively is considered. The processes of heating and vaporization of working fluids 4-8-9-1, 14-18-19-11, as well as the processes of their cooling and condensation 2-7-3 and 12-17-13 are shown in Figure 4 as isobaric.

The possibility of increasing the energy efficiency of engine cycles and the production of electrical energy is limited by the temperature of hot and cold sources of heat. Maximum efficiency will occur when the temperature of the working fluid will differ from the temperatures of these sources by an infinitely small value. However, the transfer of heat in these cases will require an infinitely large heat exchange surface of heat exchangers, therefore, it is practically impossible to implement such cycles. The condition for the practical implementation of the cycles is the difference between the temperature of the working fluid and the temperatures of the heating and cooling media by a finite value. This condition will be satisfied if the temperature differences at the outlet of heat exchangers and in the sections, in which the heated medium begins to boil or the cooled medium to condense, will be more than some minimum, i.e., if in each (j) of the characteristic cross section

$$
\Delta t_{\mathrm{j}} \geq \Delta t_{\mathrm{jmin}}
$$

where $\Delta t_{\mathrm{j}}$ and $\Delta t_{\mathrm{j} \text { min }}$ - the elements of multiple actual $\Delta t_{\mathrm{j}} \in T$ and minimum boundary temperature differences $\Delta t_{\mathrm{j} \text { in }} \in T_{\min }$ at characteristic sections of heat exchangers, ${ }^{\circ} \mathrm{C}$.

$$
\begin{gathered}
T=\left\{\Delta t_{g 1}, \Delta t_{g 2}, \Delta t_{g 3}, \Delta t_{g 4}, \Delta t_{\mathrm{hw} 2}, \Delta t_{\mathrm{c}}, \Delta t_{\mathrm{c} 1}, \Delta t_{\mathrm{c} 2}, \Delta t_{\mathrm{cw} 1}, \Delta t_{\mathrm{c} 7}\right\}, \\
T_{\min }=\left\{\Delta t_{\mathrm{g} 1 \text { min }}, \Delta t_{\mathrm{g} 2 \min }, \Delta t_{\mathrm{g} 3 \min }, \Delta t_{\mathrm{g} 4 \min }, \Delta t_{\mathrm{hw} 2 \min }, \Delta t_{\mathrm{cmin}}, \Delta t_{\mathrm{c} 1 \text { min }}, \Delta t_{\mathrm{c} 2 \min }, \Delta t_{\mathrm{cw} 1 \min }, \Delta t_{\mathrm{c} 7 \min }\right\},
\end{gathered}
$$




$$
\begin{gathered}
\Delta t_{\mathrm{g} 1}=t_{\mathrm{g} 1}-t_{11}, \\
\Delta t_{\mathrm{g} 2}=t_{\mathrm{g} 2}-t_{1}, \\
\Delta t_{\mathrm{g} 3}=t_{\mathrm{g} 3}-t_{10}, \\
\Delta t_{\mathrm{g} 4}=t_{\mathrm{g} 4}-t_{4}, \\
\Delta t_{\mathrm{hw} 2}=t_{\mathrm{hw} 2}-t_{5}, \\
\Delta t_{\mathrm{c}}=t_{\mathrm{c}}-t_{8}, \\
\Delta t_{\mathrm{c} 1}=t_{\mathrm{c} 1}-t_{18}, \\
\Delta t_{\mathrm{c} 2}=t_{17}-t_{\mathrm{c} 2}, \\
\Delta t_{\mathrm{cw} 1}=t_{3}-t_{\mathrm{cw} 1}, \\
\Delta t_{\mathrm{c} 7}=t_{7}-t_{\mathrm{c} 7},
\end{gathered}
$$

where $t_{1}, t_{3}, t_{4}, t_{5}, t_{7}, t_{8}, t_{10}, t_{11}, t_{17}, t_{18}$ - temperature of the working fluids at the characteristic points of the cycle; $t_{\mathrm{c}}$ - temperature of the heating medium at the sections of the heat exchanger where the boiling of working fluid begins; $t_{\mathrm{c} 1}$ - temperature of exhaust gases at the sections of high temperature exhaust heat exchanger where the boiling of the working fluid of high-temperature circuit begins; $t_{\mathrm{c} 2}$ - temperature of low-boiling working fluid at the section of condenser - evaporator where the condensation of the working fluid of the high-temperature circuit begins; $t_{\mathrm{c} 7}$ - the temperature of cooling water at the section of the condenser where working fluid condensation begins; $t_{\mathrm{cw} 1}-$ the temperature of the cooling water at the inlet of the condenser.

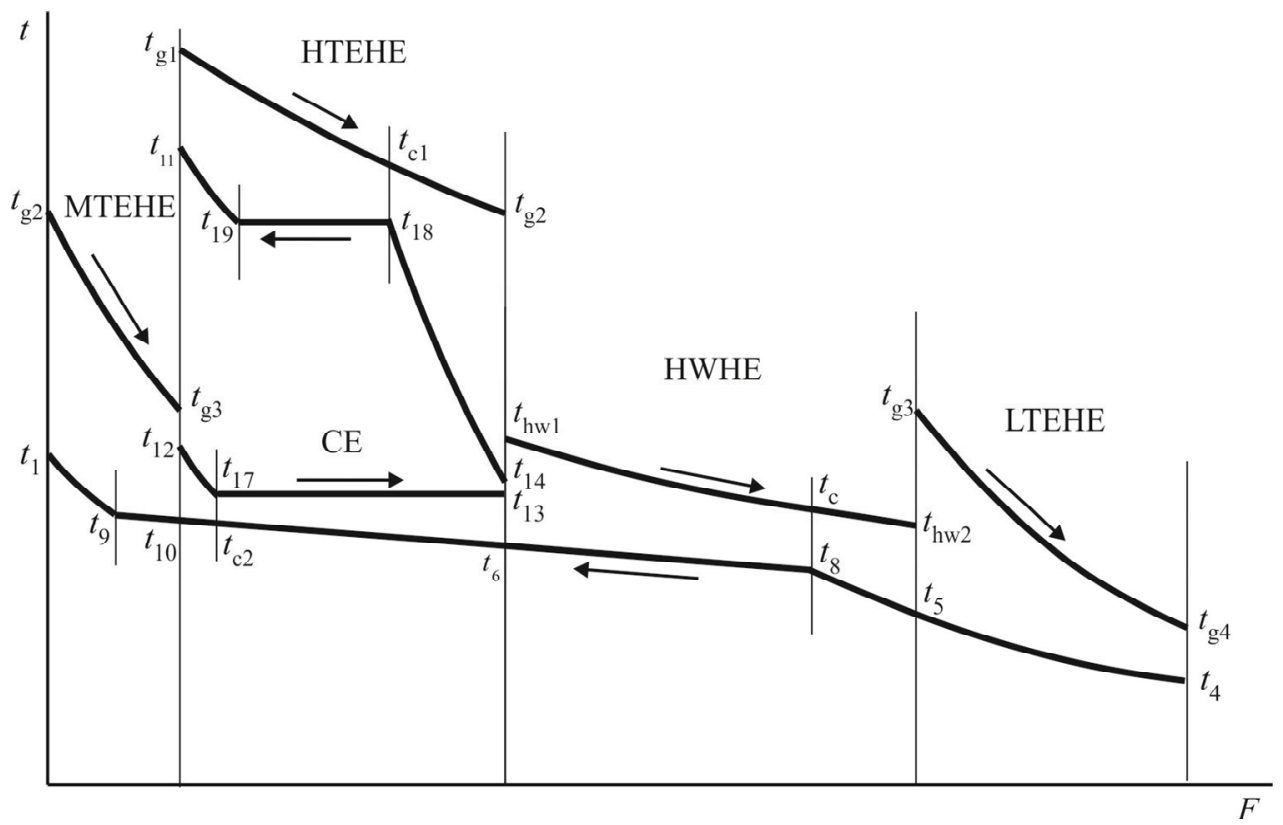

Fig. 5. The changes of the temperature media at the heat exchanges of two-circuit power generation unit. 
The ratio between the temperatures of the heating and heated media at their movement in heat exchangers along the heat exchange surface $F$ is shown in Figure 5.

With a given composition of exhaust gases, their mass flow rate $m_{\mathrm{g}}$, temperature at the inlet to the high-temperature exhaust heat exchanger $t_{\mathrm{g} 1}$, thermal power of the hot water heat exchanger $Q_{\mathrm{hwhe}}$, temperature of hot water at its inlet $t_{\mathrm{hw} 1}$ and outlet $t_{\mathrm{hw} 2}$, the calculation is reduced to determining such values of exhaust gas temperatures, $t_{\mathrm{g} 3}, t_{\mathrm{g} 4}$ and the condensate temperature of the working medium of the high-temperature circuit $t_{13}$, at which under the conditions of restrictions (1) the generated electric power will be maximum

$$
N_{\mathrm{el}}=f\left(t_{\mathrm{g} 2}, t_{\mathrm{g} 3}, t_{\mathrm{g} 4}, t_{13}\right) \rightarrow \max .
$$

The calculation is carried out by the method of successive approximations. The formation of the vector of the sought-for parameters $t_{\mathrm{g} 2}, t_{\mathrm{g} 3}, t_{\mathrm{g} 4}, t_{13}$ at each calculated iteration is determined by the method of finding the optimal solution, which is the method of complexes [9, 10]. To form the vector $t_{\mathrm{g} 2}, t_{\mathrm{g} 3}, t_{\mathrm{g} 4}, t_{13}$ the parameters of the thermodynamic cycles and the thermal mode of the PGU circuits are calculated. Unknown parameters at characteristic points of cycles are determined as a result of jointly solving the equations of thermodynamic processes in elements of the PGU, the equations of state of the working fluids, and the equations of material and energy balance of individual elements, as well as circuits and the PGU as a whole.

After checking the compliance of the calculated thermal mode with the constraint system (1) in the direction of improving the solution of the problem, a new vector of the desired parameters is formed. The calculation is repeated until the specified accuracy is reached.

\section{Results and discussion}

Simulation of thermal modes of the PGU was performed for the conditions of utilization of the secondary heat of the gas engine JMS 620 with the following initial data:

- exhaust gases temperature at the inlet of the high-temperature exhaust heat exchanger $t_{\mathrm{g} 1}=420.6^{\circ} \mathrm{C}$;

- exhaust gases flow rate, $m_{\mathrm{g}}=4.872 \mathrm{~kg} / \mathrm{s}$;

- cooling water temperature at the inlet and outlet of the hot water heat exchanger $t_{\mathrm{hw} 1}=88.6^{\circ} \mathrm{C}, t_{\mathrm{hw} 2}=70^{\circ} \mathrm{C}$;

- hot water heat exchanger heat load $Q_{\text {hwhe }}=1358 \mathrm{~kW}$;

- cooling water temperature at the inlet and outlet of the low-temperature circuit condenser $t_{\mathrm{cwl}}=20^{\circ} \mathrm{C}, t_{\mathrm{cw} 2}=25^{\circ} \mathrm{C}$;

- minimal temperature difference at the condenser $\Delta t_{\mathrm{cw} 2}=5{ }^{\circ} \mathrm{C}$;

- pressure, temperature and relative humidity of methane-air mixture, $p_{\text {init }}=101.3 \mathrm{kPa}$, $t_{\text {init }}=30{ }^{\circ} \mathrm{C}, \varphi_{\text {init }}=0.80$;

- exhaust gas pressure $p_{\mathrm{g}}=101.3 \mathrm{kPa}$;

- the coefficient of excess air ration at initial mixture of methane-air mixture $\alpha=1.9$;

- turbine and pump isentropic efficiency $\eta_{\mathrm{st}}=0.7, \eta_{\mathrm{sp}}=0.7$;

- turbine and pump mechanical efficiency $\eta_{\text {mech }}=0.97$;

- motor and electric generator efficiency $\eta_{\mathrm{el}}=0.95$.

In order to simplify the analysis of the simulation results, the minimum temperature pressures were assumed to be the same in all exhaust heat exchangers $\Delta t_{\mathrm{g} 1 \text { min }}=\Delta t_{\mathrm{g} 2 \min }=\Delta t_{\mathrm{g} 3 \min }=\Delta t_{\mathrm{g} 4 \min }=\Delta t_{\mathrm{g} \min }$, hot water heat exchanger and condenserevaporator $\Delta t_{\mathrm{ce} \text { min }}=\Delta t_{\mathrm{hw} 2 \min }=\Delta t_{\mathrm{min}}$. The values of $\Delta t_{\mathrm{g} \text { min }}$ are ranged from 4.5 to $45^{\circ} \mathrm{C}$, and $\Delta t_{\min }$ from 1.5 to $15^{\circ} \mathrm{C}$ with a ratio of $\Delta t_{\mathrm{g} \min } / \Delta t_{\min }=3.0$. 
On the bases of calculation results the diagrams Figures 6 and 7 have been drawn.

The diagrams show the influence of temperature difference limitations on the total utilized heat output $Q_{\mathrm{ut}}$, the heat output of the exhaust heat exchangers $Q_{\text {htehe }}, Q_{\text {mtehe, }}, Q_{\text {ltehe }}$, the total generated electrical power $N_{\mathrm{el}}$, and the electrical power generated in the low $N_{\text {ell }}$ and high $N_{\mathrm{el} 2}$ temperature circuits of the PGU.

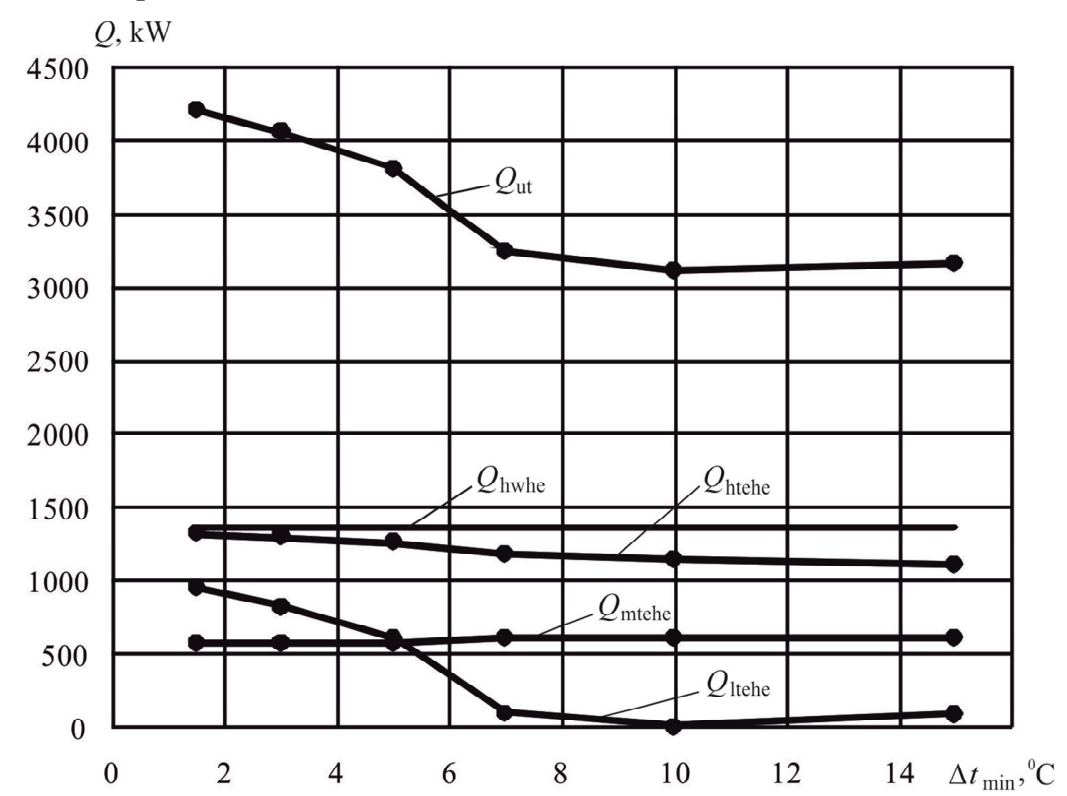

Fig. 6. Variation of thermal power and total thermal power utilized of heat exchangers with temperature differences.

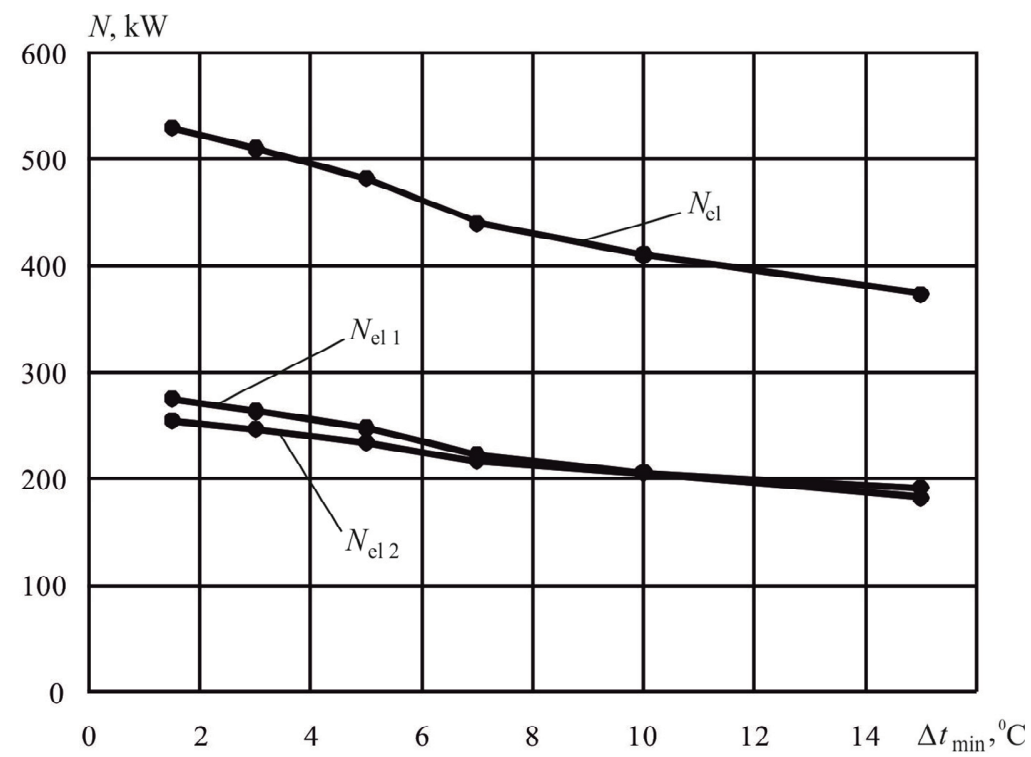

Fig. 7. Variation of electrical power generated in low-, high-temperature circuits and PGU.

Data analysis shown in the figures demonstrates that:

- as temperature differences in heat exchangers decreases both generated electric and 
thermal power increase. Thermal power increase is caused mainly by the utilization of lowgrade heat of exhaust gases in the low-temperature exhaust heat exchanger;

- the contribution of the low and high temperature circuits of the PGU to the total production of electrical energy are approximately equal;

- from utilized heat output up to $4200 \mathrm{~kW}$, the PGU allows generating up to $520 \mathrm{~kW}$ of electrical power.

Compared to the single-loop PGU (Fig. 2), the dual-circuit one allows generating 1.9 times more electrical energy from utilized heat. Its efficiency of the conversion of secondary heat into electricity reaches $12.3 \%$, which leads to an increase in the overall efficiency of the gas engine in electricity generation from 42.9 to $50.0 \%$.

\section{Conclusions}

The schema for the utilization of gas engine secondary heat by converting it into electrical energy by a dual-circuit PGU with various working fluids in the circuits has been developed. A method and an algorithm for calculating the most efficient thermal regime of the PGU under the conditions of given constrains on temperature differences in heat exchangers have been developed. On the basis of mathematical modelling of thermal modes, it has been found that, under the conditions of the gas engine JMS 620, it is possible to utilize up to $4200 \mathrm{~kW}$ of thermal power and to obtain from it up to $520 \mathrm{~kW}$ of electrical power. The efficiency of conversion of secondary heat into electricity reaches $12.3 \%$, which leads to an increase in the overall efficiency of the gas engine unit for generating electricity from 42.9 to $50.0 \%$. The simulation results indicate the promising practical implementation of the proposed technical solution.

\section{References}

1. Bulat, A., Chemeris, I. (2006). Nauchno-tekhnicheskiye osnovy sozdaniya shakhtnykh kogeneratsionnykh energeticheskikh kompleksov. Kiev: Naukova dumka

2. Samusya, V., Oksen, Y., Radiuk, M. (2013). Heat pumps for mine water waste heat recovery. Proceedings of the international scientific and technical conference "Mining of mineral deposits", 153-157

3. Pivnyak, G., Samusia, V., Oksen, Y., Radiuk, M. (2014). Parameters optimization of heat pump units in mining enterprises. Progressive technologies of coal, coalbed methane and ores mining, 19-24

4. Oksen, Y., Samusia, O. (2014). Economic efficiency of heat pump technology for geothermal heat recovery from mine water. Progressive technologies of coal, coalbed methane, and ores mining, 191-194

5. Pivnyak, G., Samusia, V., Oksen, Y., Radiuk, M. (2015). Efficiency increase of heat pump technology for waste heat recovery in coal mines. New Developments in Mining Engineering: Theoretical and Practical Solutions of Mineral Resources Mining, 1-4

6. Kyrychenko, E., Samusya, V., Kyrychenko, V., Antonenko, A. (2015). Thermodynamics of multiphase flows in relation to the calculation of deep-water hydraulic hoisting. In: New Developments in Mining Engineering: Theoretical and Practical Solutions of Mineral Resources Mining, 305-312

7. Fedorov, S.D., Oblakevich, S.V., Radiuk, O.P. (2006). The problem of utilization coal mine methane in cogeneration plants and ways to solve it on the example of the mine name by O. Zasiadko. Promelectro, 5, 35-39 
8. Oksen, Yu.I., Radiuk, M.V. (2009). Investigation effectiveness of the use of secondary heat gas piston installations for electricity generation. Geotekhnicheskaya Mekhanika [Geo-technical Mechanics], 81, 200-207

9. Bunday, B. (1988). Metody optimizatsiyi. Vvodny kurs. Moskva: Radio i sviaz

10. Reclaitis, G., Ravindran, A., Ragsdell, K. (1986). Optimizatsiya v tekhnike. Moskva: Mir 